\title{
FLEXIBLE MICROWAVE ABSORBER BASED ON STRONTIUM FERRITE-RUBBER COMPOSITE FOR X-BAND APPLICATIONS
}

\author{
Dhruba Jyoti Gogoi ${ }^{1}$, Nidhi S Bhattacharyya ${ }^{2}$ \\ ${ }^{1}$ Microwave Engineering Laboratory, Department of Physics, Tezpur Central University, Napaam, Sonitpur, Assam- \\ 784028, India \\ ${ }^{2}$ Microwave Engineering Laboratory, Department of Physics, Tezpur Central University, Napaam, Sonitpur, Assam- \\ 784028, India
}

\begin{abstract}
Silicone rubber based composite with nano sizestrontium ferrite $\left(\mathrm{SrFe}_{12} \mathrm{O}_{19}\right)$ as inclusion have been fabricated with a view to develop high dielectric loss, flexible and thin single layer microwave absorbers and their reflection loss and microwave characterization were studied in the X-band (8.2-12.4 GHz) of microwave frequencies. M-type hexagonal strontium ferrite $\left(\mathrm{SrFe}_{12} \mathrm{O}_{19}\right)$ particles have been prepared from nitrate precursors using co-precipitation technique. The nano size of strontium ferrite is confirmed by XRD analysis. The complex Permittivity $\left(\varepsilon_{r}=\varepsilon_{r}^{\prime}-\varepsilon_{r}^{\prime \prime}\right)$ and permeability $\left(\mu_{r}=\mu_{r}^{\prime}-\mu_{r}^{\prime /}\right)$ of strontium ferrite $\left(\mathrm{SrFe}_{12} \mathrm{O}_{19}\right)$ have been measured for various weight fraction of the composite. Strontium ferrite when impregnated into the rubber matrix imparts the required complex dielectric permittivity and permeability to the composite. Thickness of the absorber is an important criterion influencing the absorber characteristics. Composites samples of $3.5 \mathrm{~mm}$ and $4 \mathrm{~mm}$ thickness are found to absorb over the whole X-band frequencies with $-10 \mathrm{~dB}$ reflection loss. A minimum reflection loss $\left(S_{11}\right)$ of $-15 \mathrm{~dB}$ is observed for the composite with weight fraction $60 \mathrm{wt}$. \% and $\tan \delta_{\varepsilon}=0.2$ (loss tangent, $\tan \delta_{\varepsilon}=\frac{\varepsilon_{r}^{\prime \prime}}{\varepsilon_{r}^{\prime}}$ ).
\end{abstract}

Keywords: microwaveabsorber, strontium ferrite, composite material.

\section{INTRODUCTION}

In recent decades the widespread development and use of the electronic and electrical equipmentin X-band (8.2-12.4 $\mathrm{GHz}$ ) frequency such as wireless communication tools, local area networks, personal digital assistant and other communication equipment have created a new kind of problemcalled electromagnetic interference (EMI).It can wreak havoc with instruments, control systems, dataprocessing equipment, and communications networksin variouscommercial and military applications. Thus, EMI poses a significant challenge to equipment designers in a world that depends on electrical and electronic devices. The more critical and sensitive the equipment, the more important is the need to shield it.To provide a suitable solution for the EMI problem, the shielding or absorbing of the electromagnetic field is taken into account to make an electromagnetic compatibility (EMC) environment. The EMI shielding can be achieved either by reflection or absorption of interfering electromagnetic wave[1].With progressive development of wireless technology thin, flexible and broadband EM wave absorption materials have attracted considerable attention as EMI shielding through absorption mechanismto today's advanced applications due to the fact that they can absorb microwave energy [23].Microwave energy, when incident on a lossy dispersive material, creates heating within the material through the interactions of the electromagnetic field with the material's molecular and electronic structure[4].
In general, radar absorbing materials (RAM) are fabricated in the form of sheets that consist of insulating polymer, like rubber, epoxy resin and magnetic or dielectric loss materials such as ferrite, carbonaceous particles [5-12].The density of the magnetic composite material for absorber is too high to use them in large quantity as filler of absorbers as it increase the weight of the absorber. Again, dielectric absorbers are thick compared to magnetic absorberleading to bulky devices and havelarger impedance mismatch at the airabsorber interface[13-14]. Therefore inrecentyears, the development of magnetic-dielectric compositematerials have attracted increasing attention ofresearchers due totheir excellent absorption characteristics. Dielectric and magnetic losses of M-type hexagonal nano-ferrites at microwave frequencies make them a special kind of absorbing material. In the present investigation, silicone rubber based composite with $\mathrm{SrF}_{12} \mathrm{O}_{19}$ as inclusions is developed with a view to develop high dielectric loss, light weight, cost effective broadband microwave absorber. The developed composite are characterized for complex permittivity in $\mathrm{X}$ band. Reflection loss of the composite is additionally addressed, using transmission line (TL) technique for conductor backed single layer structure.

Generally, there are two types of absorbers: impedance matching or broadband absorbers and resonant absorbers. Broadband absorbers are independent of a particular frequency and can therefore be effective across a broad spectrum. The resonant absorbers are frequency-dependent because of the desired resonance of the material at a 
particular wavelength. Fig.1 shows the loss mechanism of resonant type microwave absorber.

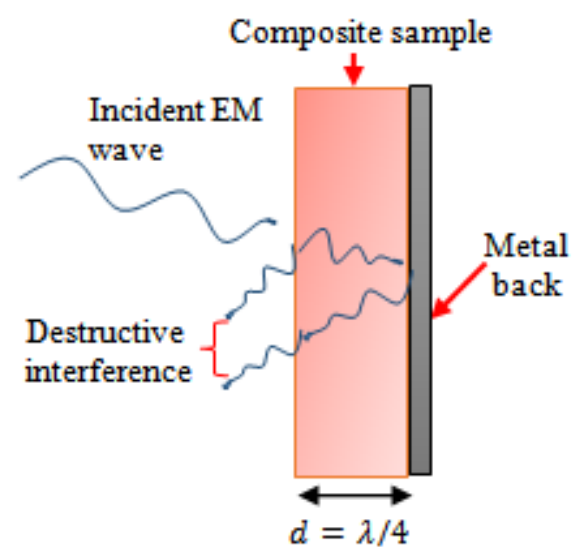

Fig 1. Schematic diagram of absorption mechanism in single layer metal back absorber

A useful visualization is that the incoming wave will be partially reflected by the front surface of the material while part is transmitted. The reflected wave undergoes a phase reversal of $\pi$. The transmitted wave then propagates through to the back of the absorber where it undergoes total reflection from the metal back and propagates back through the front face of the absorber. If the wave reflected off the front face is equal in magnitude and 180 degree out of phase

(a)

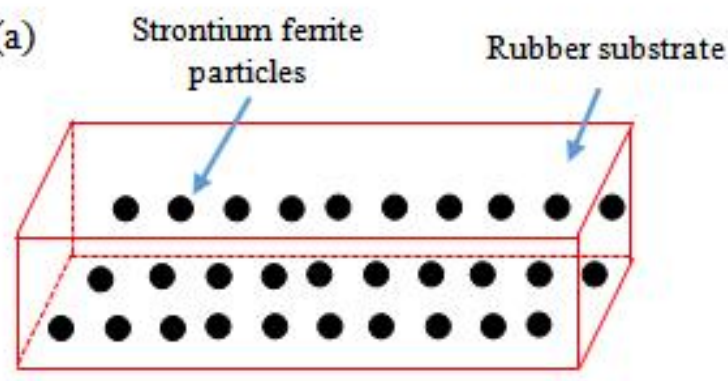

with the wave reflected off the back face then the waves will cancel and there will be no total reflection.

\section{EXPERIMENTAL}

\subsection{Preparation of strontium ferrite}

Nano sized M-type Strontium ferrite $\left(\mathrm{SrFe}_{12} \mathrm{O}_{19}\right)$ particles are prepared from nitrate precursors using co-precipitation technique. Strontium nitrate $(\geq 98 \%)$ and iron (III) nitrate nonahydrate $(\geq 98 \%)$ precursors are used as the base materials to which sodium hydroxide is added drop wise to control the size of the particles. Aqueous solutions of strontium and iron salts are prepared separately by dissolving the salts in reverse osmosis (RO) deionized water maintaining the molar ratio of strontium to ferric nitrate as 1:12 with constant magnetic stirring condition. The iron and strontium salt solutions are mixed together and heated at 70 ${ }^{\circ} \mathrm{C}$ with continuous magnetic stirring. The precipitate is dried at $100{ }^{\circ} \mathrm{C}$. The dried powder is crumbled and annealed $900{ }^{\circ} \mathrm{C}$ to get nano sized strontium ferrite particles.

\subsection{Preparation of composites}

Silicone-rubber is used as base matrix for the composite in the present investigation. Silicone rubber has good heat resistance, electrical insulation, flexible, flame and chemical resistance and is also cost effective. The prepared strontium ferrite was added to the matrix composed of silicone rubber at $60 \mathrm{wt} . \%, 50 \mathrm{wt} . \%, 40 \mathrm{wt} . \%, 30 \mathrm{wt} . \%$ and $20 \mathrm{wt} . \%$ as filler material. The mixture was homogenized by mechanical agitation, and the processed materials were poured into $(22.94 \times 10.38 \mathrm{~mm})$ molds and dried at room temperature.

Fig 2. (a)Microwave rubber based absorber filled with $\mathrm{SrFe}_{12} \mathrm{O}_{19}$ particles(b) Fabricated sample filled with $\mathrm{SrFe}_{12} \mathrm{O}_{19}$ particles

Pellets of dimensions, (22.94 X $10.38 \mathrm{X} \mathrm{h} \mathrm{mm)} \mathrm{are} \mathrm{obtained}$ for $\mathrm{X}$ band microwave characterization, where $\mathrm{h}$ is the thickness of the absorber sample.

\section{RESULTS AND DISCUSSIONS}

\subsection{X-ray diffraction analysis}


The nano sized of strontium ferrite was confirmed by X-ray diffraction (XRD) studies carried out on an advance XRD instrument using $\mathrm{Cu} \mathrm{K \alpha}$ radiation $(\lambda=1.54 \AA)$ in the scattering range $(2 \theta)$ of $20^{\circ}-80^{\circ}$ with a scan rate of $0.05^{\circ} / \mathrm{sec}$ and a slit width of $0.3 \mathrm{~mm}$. Fig. 3 . a shows glancing angle X-ray diffraction pattern of Strontium Ferrite $\mathrm{SrFe}_{12} \mathrm{O}_{19}$ nano powder. The analysis of XRD pattern reveals that the sample is in single hexagonal M-type phase. No other peak of any other component is observed. The main peak (107) observed at the XRD patterns $2 \theta=32.24$ matched with the standard XRD pattern of $\mathrm{SrFe}_{12} \mathrm{O}_{19}$ (Powder Diffraction). File, JCPDS No. 84-1531). The particle size of Hexagonal $\mathrm{SrFe}_{12} \mathrm{O}_{19}$ Was calculated to be $38.04 \mathrm{~nm}$ using Scherer's Equation [15].

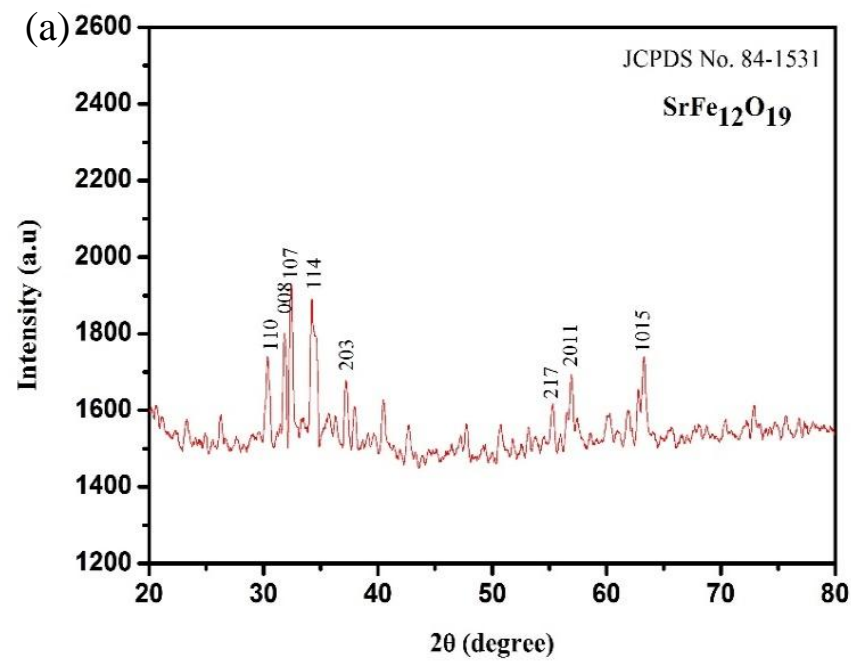

(b)

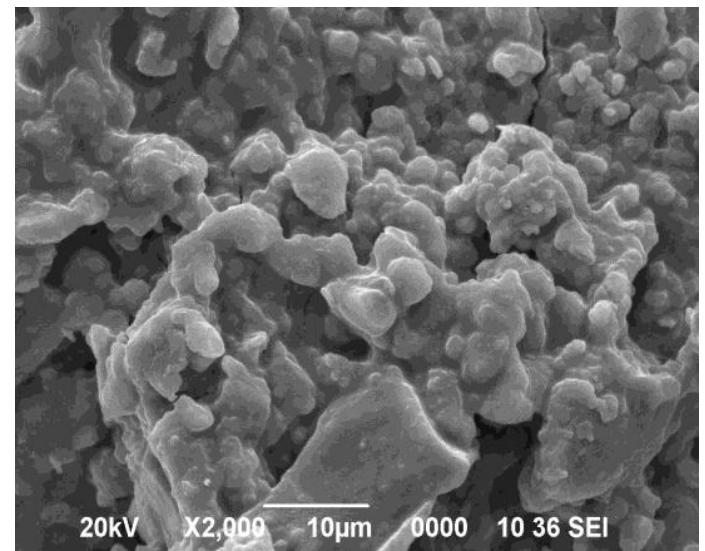

Fig.3. (a) XRD of Strontium ferrite (b) SEM image of $\mathrm{SrFe}_{12} \mathrm{O}_{19}$

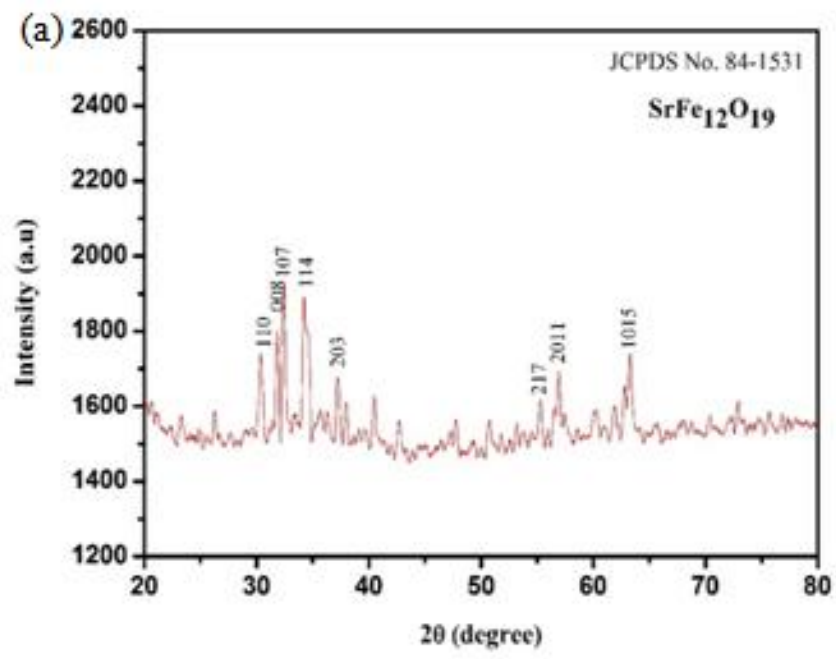

(b)

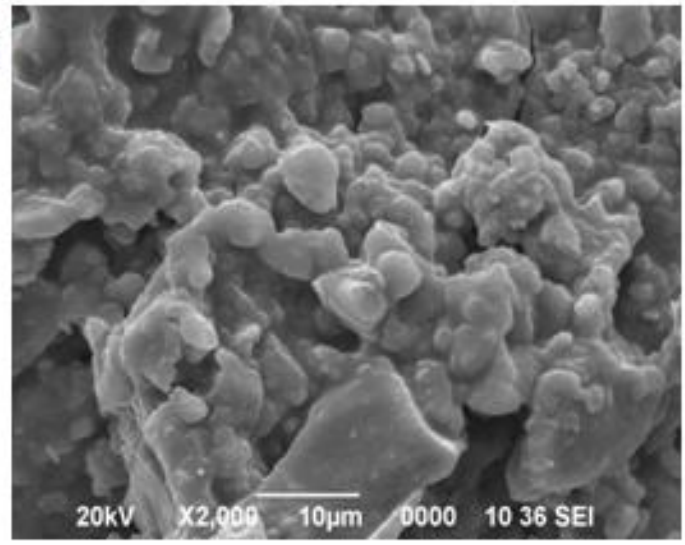

Fig.3. (a) XRD of Strontium ferrite (b) SEM image of $\mathrm{SrFe}_{12} \mathrm{O}_{19}$

Fig. 3 (b) shows the SEM image of the prepared strontium ferrite and the spherical shape of the particles have been noticed from the SEM image.

\subsection{Complex permittivity, permeability and loss}

\section{studies}

Material characterization at microwave frequency has been done by Transmission/Reflectionmethod using Agilent WR90 X11644A rectangular waveguide line compatible with Agilent E8362C vector network analyzer. Fig.4.(a) and (b) show the frequency dependence of the real part $\left(\varepsilon_{\mathrm{r}}^{\prime}\right)$ and imaginary part $\left(\varepsilon_{\mathrm{r}}^{/ /}\right)$of relative complex permittivity of strontium ferrite/silicone-rubber composites in the frequency range 8.2-12.4 GHz. Composite with 60 wt.\% of $\mathrm{SrFe}_{12} \mathrm{O}_{19}$ loading shows maximum values of $\varepsilon_{\mathrm{r}}^{\prime}$ and $\varepsilon_{\mathrm{r}}^{/ /}$approx. 5.05 and 0.89 respectively over the $\mathrm{X}$-bandfrequency. The other composites shows relatively low values of relative dielectric constant compare to $60 \%$ wt. $\%$.Higher filler concentration increases the interaction between the fillers.As strontium ferrite conductivity is quite high as compared to polymer, increasing filler content increases the effective conductivity which in turn increases the loss factor $\varepsilon_{\mathrm{r}}^{/ /}$. Fig.4. (c) shows the dielectric loss tangent of the composites, which shows that increasing filler wt. $\%$ in the composite increases 
$\left(\varepsilon_{\mathrm{r}}^{/ /} / \varepsilon_{\mathrm{r}}^{\prime}\right)$ factor. Dielectric loss near to 0.2 suggest that the material has moderate dissipation factor rather than storage capacity. Thus, the strontium ferrite/siliconerubber composite has the potential characteristics for broadband microwave absorption.Fig.4. (d)showsrectangular waveguide line compatible with Agilent E8362C vector network analyzer for material characterization.
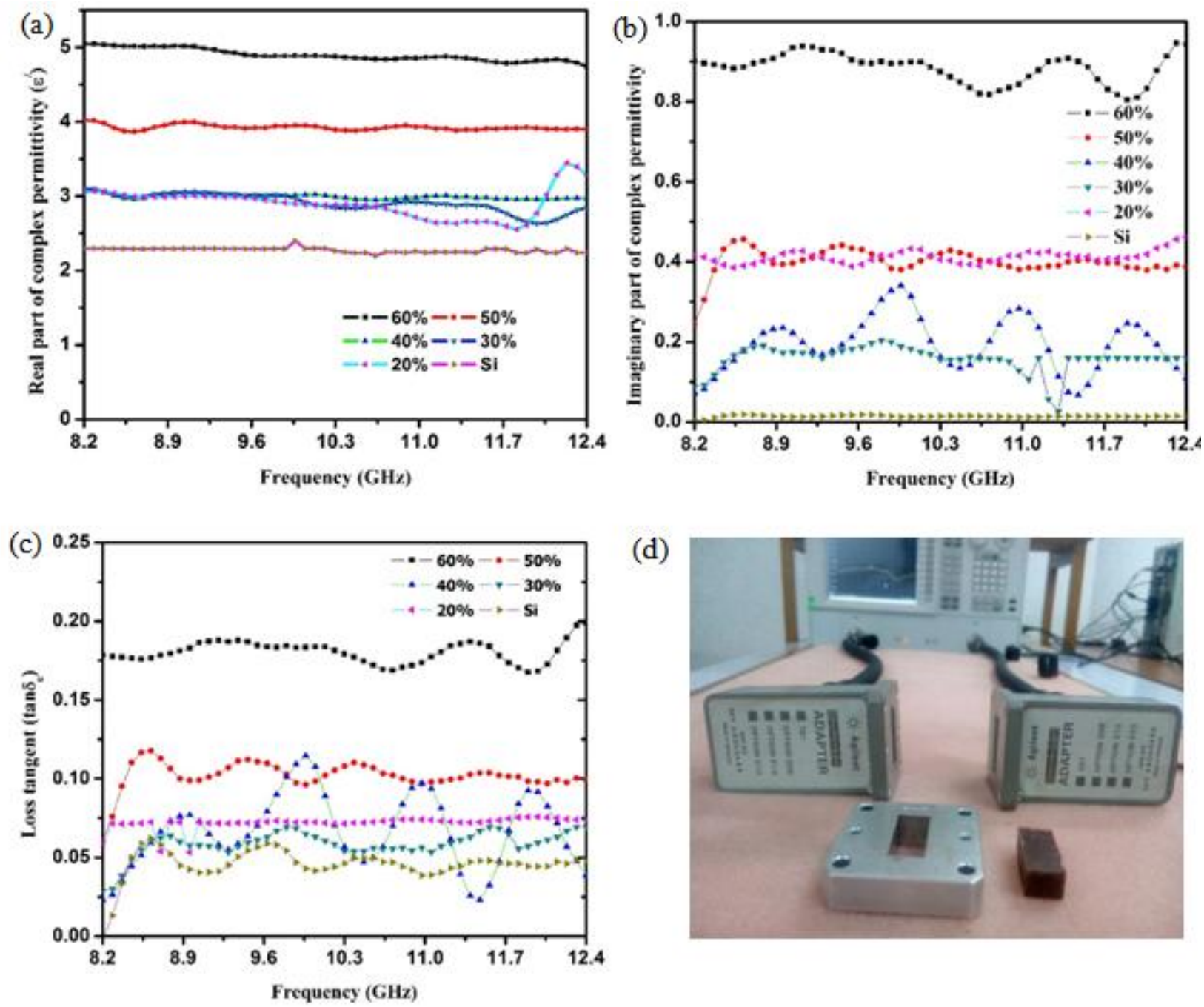

(d)

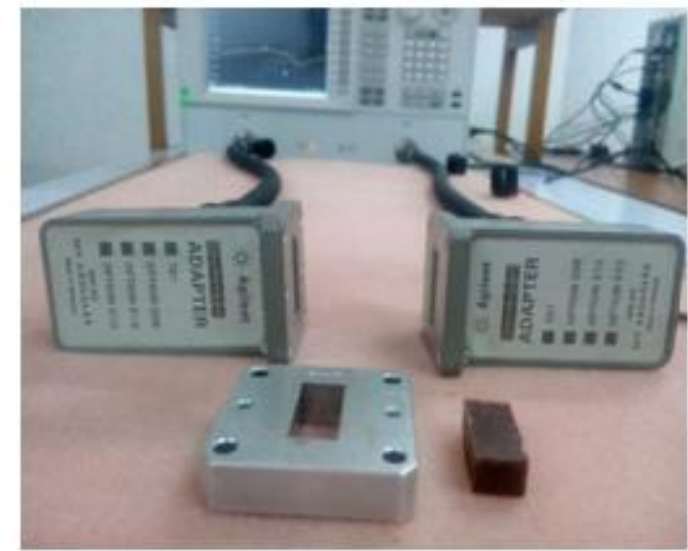

Fig.4. (a) Real part of complex permittivity (b) Imaginary part of complex permittivity (c) Dielectric loss tangent ( $\left.\varepsilon_{r}^{/ /} / \varepsilon_{r}^{\prime}\right)$ of strontiumFerrite/silicone-rubber composites and (d) Fabricated sample and wave guide techniques for material characterization

\subsection{Reflection Loss study}

Reflection loss is determined from the measured values of $\varepsilon_{r}^{\prime}$ and $\varepsilon_{r}^{/ /}$of the composites,

Thickness $\mathrm{d}(\mathrm{mm})$ $-10 \mathrm{~dB}$ bandwidth by

transmission line theory for conductor backed singlelayered structure. The reflection loss (RL) of the incident electromagneti
$(12.4-9.82)=2.58$

$$
\text { 4.2 GHz (X-band) }
$$

$(10.02-8.2)=1.82$ c wave normal to the planar single-layered structure is expressed as

$$
\begin{aligned}
& R L= 20 \log \left|\frac{Z_{\text {in }}-Z_{0}}{Z_{\text {in }}-Z_{0}}\right| \\
& Z_{\text {in }}=Z_{0} \sqrt{\frac{\mu_{r}}{\epsilon_{r}}} \tanh \left(\mathrm{j} \frac{2 \pi f d}{c} \sqrt{\mu_{r} \epsilon_{r}}\right)
\end{aligned}
$$

Where,

Fig.5.a shows the reflection loss curves of strontium ferrite/silicone-rubber composites of different thickness for weight fraction $60 \%$ wt. \%.The whole $\mathrm{X}$-band absorption has been found with $4 \mathrm{~mm}$ thickness of $60 \mathrm{wt}$. \%.

Table 1: Reflection loss at different thickness of 60 wt. \% 


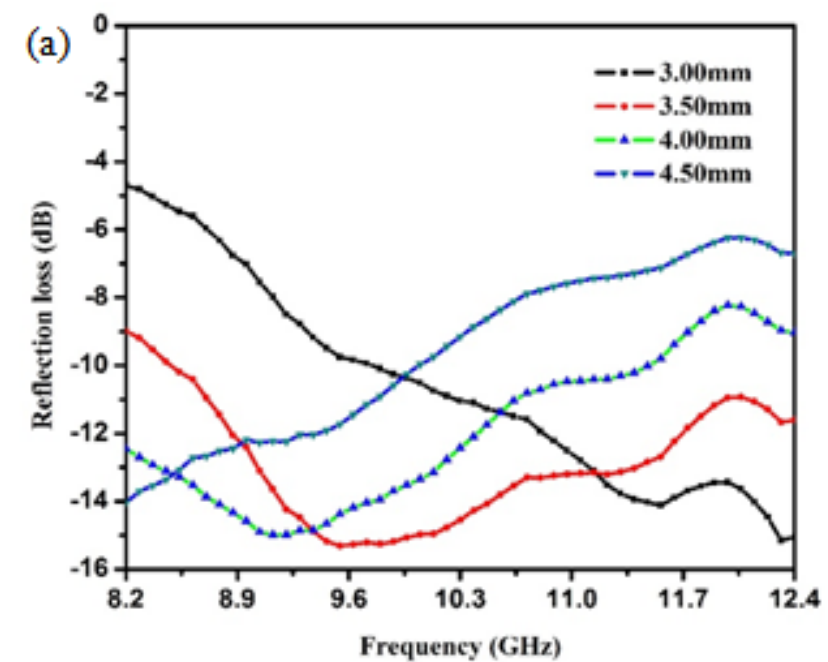

Fig.5. (a) Reflection loss curve of strontium ferrite/siliconerubber composites for $60 \mathrm{wt}$ \%

\section{CONCLUSION}

The $\mathrm{SrFe}_{12} \mathrm{O}_{19}$ synthesized by co-precipitation technique and mechanical agitation method is used to prepare composite sample with different ferrite wt. \% and complex permittivity was investigated in the frequency ranges $8.2-12.4 \mathrm{GHz}$. The nano sized strontium ferrite particle has been verified by XRD analysis. High performance microwave absorption with potential for applications in broadband frequency can be achieved using the strontium ferrite/silicone-rubber composites which have high dielectric loss compare to magnetic loss tangent over the entire X-band. Further, the developed composites are flexible and relatively cost effective. Absorption can be further enhanced by structural modifications of the absorber.

\section{REFERENCES:}

1. Hong, S. K., et al. Electromagnetic interference shielding effectiveness of monolayer graphene, Nanotechnology, 23(45), 455704, 2012.

2. Zhuo, R. F., et al. Microwave absorption properties and the isotropic antenna mechanism of $\mathrm{ZnO}$ nanotrees, Journal of Applied Physics, 104(9), 094101, 2008.

3. Chen, Y. J., et al. Microwave absorption properties of the $\mathrm{ZnO}$ nanowire-polyester composites, Applied physics letters, 84(17), 3367-3369, 2004.

4. Qin, F. \& Brosseau, C. A review and analysis of microwave absorption in polymer composites filled with carbonaceous particles, Journal of applied physics, 111(6), 061301. 2012.

5. Ohlan, A., et al. Microwave absorption properties of conducting polymer composite with barium ferrite nanoparticles in 12.4-18 GHz, Applied physics letters, 93(5), 053114-1, 2008.
6. Guo, Z., et al. Magnetic and electromagnetic evaluation of the magnetic nanoparticle filled polyurethane nanocomposites, Journal of applied physics, 101(9), 09M511, 2007.

7. Micheli, D., et al. X-Band microwave characterization of carbon-based nanocomposite material, absorption capability comparison and RAS design simulation, Composites Science and Technology, 70(2), 400409, 2010.

8. Feng, Y. B., et al. Absorbing properties and structural design of microwave absorbers based on carbonyl iron and barium ferrite, Journal of Magnetism and Magnetic Materials, 318(1), 8-13, 2007.

9. Kim, J. B., et al. Comparison study on the effect of carbon nano materials for single-layer microwave absorbers in X-band, Composites Science and Technology, 68(14), 2909-2916, 2008.

10. Ren, F., et al. Cyanate ester resin filled with graphene nanosheets and $\mathrm{CoFe}_{2} \mathrm{O}_{4}$-reduced graphene oxide nanohybrids as a microwave absorber, Applied Surface Science, 351, 40-47, 2015.

11. Esfahani, A. S., et al. Preparation and characterization of foamed polyurethane/silicone rubber/graphite nanocomposite as radio frequency wave absorbing material: The role of interfacial compatibilization, Composites Science and Technology, 72(3), 382-389, 2012.

12. Akman, O., et al. Magnetic metal nanoparticles coated polyacrylonitrile textiles as microwave absorber, Journal of Magnetism and Magnetic Materials, 327, 151-158, 2013.

13. Xu, F., et al. Microwave absorbing properties and structural design of microwave absorbers based on polyaniline and polyaniline/magnetite nanocomposite, Journal of Magnetism and Magnetic Materials, 374, 311316, 2015.

14. Xu, Y., et al. Smart absorbing property of composites with MWCNTs and carbonyl iron as the filler, Journal of Magnetism and Magnetic Materials, 343, 239-244, 2013.

15. Samikannu, K., Sinnappan, J., Mannarswamy, S., Cinnasamy, T., \& Thirunavukarasu, K. (2011). Synthesis and magnetic properties of conventional and microwave calcined strontium hexaferrite powder. Materials Sciences and Applications, 2(06), 638. 